\title{
URBAN RUNOFF: ITS SIGNIFICANCE, CHEMICAL CHARACTERISTICS, AND POSSIBLE CHEMICAL TREATMENT
}

\author{
Umid Man Joshi \\ Rajasekhar Balasubramanian \\ National University of Singapore, Singapore
}

\begin{abstract}
Most of the countries around the world including Singapore are becoming water scarce. Limited fresh water resources and growing demand of water in urban areas have intensified the search for non-conventional water resources. For countries like Singapore, which receives copious rainfall, the use of stormwater (rainfall which runs off urban areas such as roofs, roads, and vegetated surfaces) has the potential to enhance urban water supply. However, using urban landscape as catchments has its inherent challenges. Human activities introduce chemical and biological contaminants of different types into the urban runoff, affecting its quality significantly. Environmentally-friendly as well as cost-effective treatment technologies are needed to treat urban runoff at points of collection so that the treated stormwater can be used for a range of practical applications.

In order to identify the most appropriate treatment technology, it is necessary to have detailed information on the physical and chemical characteristics of urban runoff collected at a network of urban sites. As these characteristics of urban runoff largely depend on land use patterns, stormwater samples have been collected in this study from various land use sectors using automated samplers and subsequently processed in the laboratory to establish their chemical characteristics mainly in terms of trace metals, and organic compounds. Results obtained from the chemical characterization work are presented followed by the discussion on the potential of enhancing urban runoff quality through chemical treatment with a strong oxidant having multiple functions including coagulation, flocculation, and disinfection.
\end{abstract}

\section{KEYWORDS}

Urban runoff; Chemical characterization; Trace metals; Urban environment.

\section{INTRODUCTION}

Water is indispensable for human health and well-being. Global consumption of water is doubling every 20 years, more than twice the rate of human population growth. The Earth's water system can support, at most, only one more doubling of demand, estimated to occur in less than 30 years. Currently, some 450 million people in 29 countries already face water stress/scarcity. Two-thirds of the world's population is predicted to be living with serious water shortages or absolute water scarcity by 2025 , if the current growth rate in global water demand persists. In addition, the demand for potable water is centralized in and around urban areas. For the first time in history half of the global population is living in urban areas, compared to little more than one-third in 1970s. To add on to the already existing water 
scarcity, the forecast that urban population is expected to grow by $2 \%$ per year during 2000 15 , and to reach an overall $65 \%$ urban by 2050 indicates the crunching demand on fresh water supplies in the days ahead.

Limited fresh water resources, growing demand of water, environmental concern, and ever stringent water quality standards by the regulatory agencies have encouraged the scientific community to look for non-conventional water sources, and more effective, environmentally friendly treatment technologies. Technologies are now available by virtue of which waste water and even sea water can be converted to potable water, however, the excessive cost of these treatment processes and psychological barrier for the use of treated wastewater are the major constrains for implementing these technologies. A great deal of attention is now paid to alternative sources of water such as storm water catchment systems as they serve multipurpose functions.

The origin of urban stormwater runoff is the rainfall. Urban runoff is excess water, not absorbed by soil after heavy rains. It flows over surfaces such as roads, parking lots, building roofs, driveways, lawns, and gardens. Urban areas are characterized by imperviousness, where a substantial fraction of the land is made impervious by construction of structures such as buildings, roads, pavements, etc. Thus, there is a potential to use urban runoff as a substitute and/or supplementary source of much needed potable water. However, during its movement through soils and impervious surfaces, stormwater can carry a wide range of potentially harmful environmental contaminants, such as metals, oil and grease, pesticides, and fertilizers. For this reason, even when there is scarcity of water in urban areas, the conventional practice has been directed towards discharging the urban storm water as soon as possible through a network of drainage systems. Now that there is a greater interest in utilizing the runoff from urban areas, the similar systems can be used to collect the urban runoff. However, use of water from urban runoff is not straight-forward. Contradicting the traditional belief that the stormwater is contamination-free, recent studies have suggested that the stormwater could be a potential source of pollution and the concentrations of pollutants vary according to the location through which it passes $[1,2,3]$. Stormwater even from a visibly clean catchment can be a significant source of pollution $[4,5]$. Even though the quantity of urban runoff makes it justifiable to consider it as an alternative source of water, the quality is questionable. Accurate knowledge of the quality and quantity of runoff is required to develop appropriate treatment technologies. To date, there is still a lack of comprehensive data concerning quality of stormwater, especially the chemical pollutants (inorganic and organic) in runoff water from impervious surfaces like roofs, commercial, and residential areas.

\section{EXPERIMENTAL METHODOLOGIES}

\subsection{Site description}

Singapore is located at the southern tip of the Malaysian Peninsula, between latitudes $1^{\circ} 09^{\prime} \mathrm{N}$ and $1^{\circ} 29^{\prime} \mathrm{N}$ and longitudes $103^{\circ} 26^{\prime} \mathrm{E}$ and $104^{\circ} 25^{\prime} \mathrm{E}$. The study area lies in the south western part of Singapore around 1000 meters away from open sea. Three sites representing different land use patterns were chosen in close proximity in order to reduce the impact of atmospheric variability over the sites. Roof runoff was collected from an outlet of a pipe, whereby, rainwater passes through roof, and the gutter and is collected before it touches the ground. Water samples from a commercial area were collected from a drain where some renovation works were also being carried out. Samples were also collected from a residential area, with 
housing blocks, gardening, and basic facilities like parking and walkway shades (metal/plastic roofing for walkways from one block to another).

\subsection{Sample collection}

Samples were colleted from the three urban sites for a year from February 2005 to January 2006. The $\mathrm{pH}$ of water samples were measured soon after they were brought to the laboratory. The samples were then filtered through $0.45 \mu \mathrm{m}$ nylon membrane filter (Whatman, Cat. No.7404-004). The conductivity of the filtered samples was measured prior to separating them into two fractions. One fraction was acidified with $\mathrm{HNO}_{3}$ (analytical grade, Fluoka, France) so as to keep the $\mathrm{pH}$ to less than 2, and was subsequently analyzed for trace metals by Inductively Coupled Plasma - Mass Spectroscopy (ICP-MS). Acid blanks $\left(2 \% \mathrm{HNO}_{3}\right.$ in Ultra-pure water) were used for every set of samples to account for contamination, if any, through acid addition of $\mathrm{HNO}_{3}$. The other fraction was stored in amber colored glass bottle following the addition of thymol to preserve organic species in the samples. The organic compounds were analyzed using Gas chromatography - Mass Spectroscopy (GC-MS).

\subsection{Sample analysis}

ICP-MS (Perkin Elmer Elan 6100) was used for the analysis of trace metals in the samples. The instrument was operated as recommended by the manufacturer and was optimized daily. The detailed description on the ICPMS parameters is described in our previous reports [6]. Seven point calibration $(1,5,10,20,40,60$ and $100 \mu \mathrm{g} / \mathrm{L})$ was performed for 13 trace metals, and the regression coefficients for all 13 trace metals were better than 0.999. Sample handling and preparation were carried out in a laminar flow hood equipped with a HEPA (HighEfficiency Particulate Air) filter to prevent contaminations. The final concentrations of metals in the urban runoff samples are reported after the acid blank correction.

GC-MS (Model QP2010, Shimadzu Inc, Kyoto, Japan) fitted with a DB-5MS 5\%-phenylmethylpolysiloxane $30 \mathrm{~m}$ long x $0.2 \mathrm{~mm}$ internal diameter $\times 0.25 \mathrm{~mm}$ film thickness capillary column ( $\mathrm{J} \&$ W Scientific, CA, USA) was used. The GC-MS was operated under the following conditions: splitless injection of $2 \mathrm{ml}$, split opening after 30 seconds, and injector temperature at $280^{\circ} \mathrm{C}$; the oven temperature program was $50^{\circ} \mathrm{C}$ (hold $2 \mathrm{~min}$ ); $50^{\circ} \mathrm{C}$ to $200^{\circ} \mathrm{C}$ at $10^{\circ} \mathrm{C}$ min $^{-1}$ (hold $1 \mathrm{~min}$ ); $200^{\circ} \mathrm{C}$ to $300^{\circ} \mathrm{C}$ at $5^{\circ} \mathrm{C}$ per minute (hold $8 \mathrm{~min}$ ). The detector was run in electron impact mode with electron energy of $70 \mathrm{eV}$ and ion source temperature of $230^{\circ} \mathrm{C}$. Helium at a constant flow rate of $0.8 \mathrm{~mL}$ per minute was used as carrier gas. PAHs were monitored using selected ion monitoring mode (SIM).

\section{RESULTS AND DISCUSSION}

\subsection{Heavy metals}

Heavy metals are one of the major concerns in urban runoff because of their potential toxicity and widespread presence. Sources of trace metals in urban stormwater runoff are numerous and complex. Metals cannot be chemically transformed or destroyed, thus making them persistent [2]. Though some metals are present in trace levels, they are still of concern because of their potential toxicity. The International Agency for Research on Cancer (IARC) classifies $\mathrm{As}$ and its compounds, $\mathrm{Cd}$ and its compounds, $\mathrm{Cr}$ (VI) compounds, $\mathrm{Ni}$ compounds as Class I agents (carcinogenic to humans), $\mathrm{Pb}$ compounds as Class 2A agents (probably carcinogenic to humans), and $\mathrm{Pb}$ and $\mathrm{Ni}$ as Class 2B agents (possibly carcinogenic to humans). Some metals are necessary for vital metabolic processes, for example, $\mathrm{Fe}$ and $\mathrm{Cu}$ are required for the synthesis of hemoglobin; $\mathrm{Mn}$ and Fe are constituents of some enzymes; 
$\mathrm{Zn}$ is required for proper functioning of enzymes, growth of tissue and healing of wounds; $\mathrm{Cr}^{3+}$ is necessary for production and functioning of insulin. However, even the essential metals, if present in higher concentration, are toxic. The study reports the concentration of 13 trace metals ( $\mathrm{Al}, \mathrm{As}, \mathrm{Cd}, \mathrm{Cu}, \mathrm{Co}, \mathrm{Cr}, \mathrm{Fe}, \mathrm{Mn}, \mathrm{Ni}, \mathrm{Pb}, \mathrm{Ti}, \mathrm{V}$ and $\mathrm{Zn}$ ) in runoff from roof, residential, and commercial areas in Singapore.

Figure I compares the average concentration of trace metals for the three sites; roof runoff, runoff from residential and commercial areas. Since the variation in concentrations among various trace metals is quite large, the data are presented in log-graph. $\mathrm{Al}, \mathrm{Fe}$, and $\mathrm{Zn}$ are the three most abundant metals in all runoff samples accounting for more than $80 \%$ of the total metals.

Variations were noted in the concentration of trace metals from one sample to another in each land use categories and among the categories. However, the variations among the different categories were dominant. Various factors are reported to influence the concentration of metals in urban runoff which include: number of days antecedent to rainfall, intensity of rainfall, atmospheric deposition, surface over which the runoff passes, anthropogenic activity in the area considered, etc $[2,4,7]$. In this study, as the sampling locations were in close proximity, the most probable reason for this variation is the land use change.

The concentrations of $\mathrm{Pb}$ and $\mathrm{V}$ in roof runoff were particularly elevated by more than an order of magnitude compared to the rain water concentration. Leaded gasoline has been phased out from Singapore since 1998, thus resulting in lower concentration of lead in rainwater. The excess concentration of $\mathrm{Pb}$ in roof runoff could be due to the wash out of the settled dust particles on the roof, or the leaching of $\mathrm{Pb}$ from freshly painted building surfaces; Davis et al. [2] suggested that lead could predominantly come from building walls. On the other hand, the main sources of $\mathrm{V}$ include combustion of fossil fuels, steel industry emissions, dyes, inks and paints [8]. As the study area is located at a downwind direction of a major industrial area in Singapore, wet and dry deposition of pollutants emitted from the local industries such as petroleum refineries is most likely the major contributor of $\mathrm{V}$ in the runoff samples. The concentration of some trace metals $(\mathrm{Cu}, \mathrm{Fe}, \mathrm{Pb}, \mathrm{Zn}$, and $\mathrm{V})$ was lower in residential areas compared to those in the roof runoff. The major factors that could be responsible for this trend could be dry deposition of coarse particulate matter on the roof that is easily washed off $[9,10,11]$. 


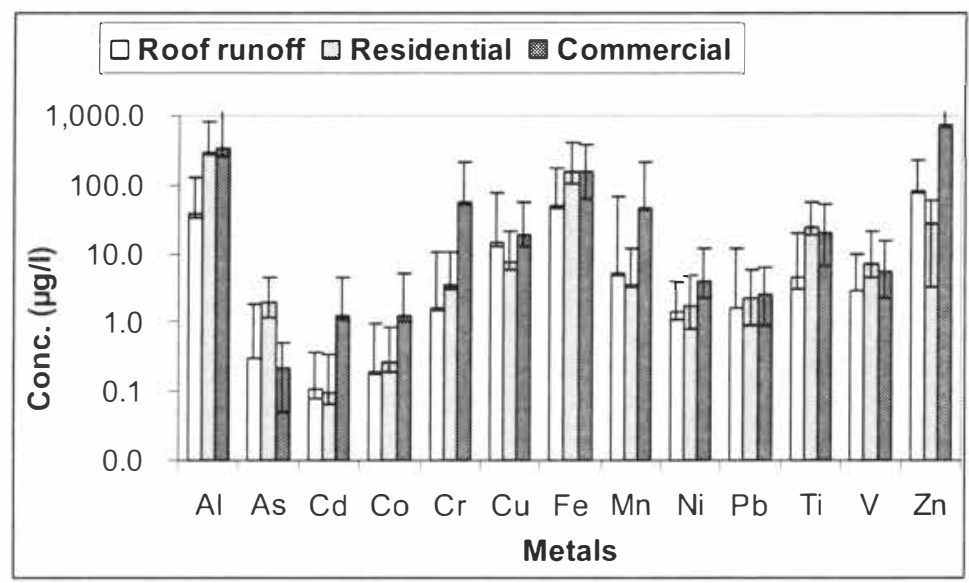

Figure I. Average concentration of trace metals in residential and commercial site.

In the case of the residential area, $\mathrm{Cu}, \mathrm{Mn}$, and $\mathrm{Zn}$ are found to decrease in concentration even as compared to rain while the rest of the trace metals were elevated by certain factors, highest being $\mathrm{Pb}$ (6.9), $\mathrm{Al}$ (5.2), $\mathrm{V}(2.9)$, and $\mathrm{Cr}(1.7)$. As the substantial fraction of runoff passes through vegetated areas (soil) in residential areas, it is likely that soil/vegetation acts as a sink for some of these trace metals, while it leaches out other metals [9]. The enrichment of $\mathrm{Pb}$ could also be because of its leaching out the ones that was deposited onto the soil during the earlier days of use of leaded gasoline [3] in addition to building walls.

The quality of stormwater in commercial areas showed some distinct patterns. As compared to rain water around the same location, the stormwater from commercial areas had $\mathrm{Co}$ and $\mathrm{Cr}$ concentrations higher by an order of magnitude while $\mathrm{Cd}$ was higher by three orders of magnitude. Cobalt oxides are used in paints, and can also be leached out from corrosion of high-strength alloys; sources of chromium include corrosion of welded metal plating, wear of bearings and brushings, dyes, paints etc; and cadmium is leached out from corrosion of galvanized metals [8]. These sources were present in minor or major form in commercial areas as the renovation works were in progress during the sampling period, thus, the rise in the above mentioned trace metal concentrations.

\subsection{Metals in sequential urban runoff samples}

Investigation of temporal variation of pollutants for longer storm events was done using an automated sampler in the residential area. The sampler was programmed to take samples every 15 minutes. It can be seen that crustal metals like $\mathrm{Al}$ and $\mathrm{Fe}$ are found to be much higher in concentration up to an order of magnitude as compared to rain water concentration. Even if the solubility of crustal metals is relatively low, the acidity of rain water (average $\mathrm{pH}$ 4.2 in Singapore, Hu et al., [12] is expected to enhance the solubility of these metals. Other factors include soil characteristics such as soil $\mathrm{pH}$, total carbon content, total metal content etc. [13]. The results also revealed that most of the metals showed first flush phenomenon (rising of pollutants in the initial part of a storm event) in majority of storm events. However, the time at which highest concentration appeared differed from one metal to another. Figure 2 
shows pollutograph for some of the trace metals for a storm event. Factors such as physiochemical form of metal particle association, and the travel time for the metals from the point of origin to the sampling site could be responsible for the variations. In addition, changes in anthropogenic activity during the storm event, and other variables play a part in differential leaching of trace metals. Most importantly, as the intensity of rainfall is not the same throughout the storm event, the fluctuation of concentration of trace metals in the natural system is not unusual.
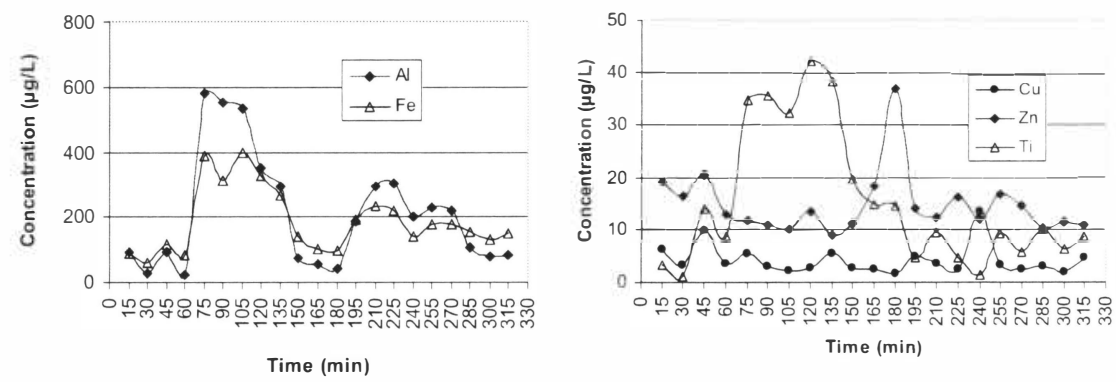

Figure 2. Trace metal concentration in urban stormwater runoff.

\subsection{Polycyclic aromatic hydrocarbons}

As the concentration of Polycyclic aromatic hydrocarbons (PAHs) are in trace levels, sensitive analytical methods were used for the extraction and analysis with the use of internal standards. Solid phase micro-extraction (SPME) was used to extract the organic pollutants from the environmental matrix and analyzed using GC-MS. The PAHs observed in this study were the 16 priority compounds listed by USEPA [14]: naphthalene (Nap), acenaphthylene (Acy), acenaphthene (Ace), fluorene (Flu), phenanthrene (PA), anthracene (Ant), fluoranthene (Flt), pyrene (Pyr), benz[a]anthracene $(\mathrm{BaA})$, chrysene (Cry), benzo[b]fluoranthene (BbF), benzo[k]fluoranthene (BkF), benzo[a]pyrene (BaP), dibenz[a,h]anthracene (DBA), indeno[1,2,3-c,d]pyrene (IND) and benzo[g,h,i]perylene (BghiP).

The average concentrations and the range (minimum and maximum) of the PAHs in the dissolved phases of the stormwater are given in Table 1. The sum of concentrations of 16 PAHs of individual storm events ranged from 506 to $1940 \mathrm{ng} / \mathrm{L}$ with an average concentration of $1143 \mathrm{ng} / \mathrm{L}$. Although these values are relatively lower than the values reported in the literature $[15,16,17,18]$, they are still much higher than the drinking water standards of 200 $\mathrm{ng} / \mathrm{L}$. Thus, sufficient care should be exercised while using the urban runoff for portable purposes by selecting proper treatment technology to remove the dissolved organic pollutants. In addition, the six carcinogenic PAHs, as described by the International Agency for Research on Cancer IARC ( $\left.\Sigma 6 \mathrm{PAH}_{\mathrm{CARC}}=\mathrm{BaA}, \mathrm{BbF}, \mathrm{BkF}, \mathrm{BaP}, \mathrm{DBA}, \mathrm{IND}\right)$ ranged from 49 to 887 $\mathrm{ng} / \mathrm{L}$, with an average value of $318 \mathrm{ng} / \mathrm{L}$, which is again higher than the drinking water standard, thus demanding special attention during treatment. 
Table I. Concentration of PAHs in Dissolved phase of stormwater:

\begin{tabular}{ccc}
\hline & \multicolumn{2}{c}{ Dissolved Phase } \\
Compound & Average (ng/L) & Range (ng/L) \\
\hline Naphthalene (Nap) & 365 & $20-98 \mathbf{0}$ \\
Acenaphthylene (Acy) & 111 & $3-340$ \\
Acenaphthene (Ace) & 26 & $8-61$ \\
Fluorene (Flu) & 29 & $27-116$ \\
Phenantherene (PA) & 100 & $32-244$ \\
Anthracene (Ant) & 10 & $3-95$ \\
Fluoranthene (Flt) & 8 & $3-131$ \\
Pyrene (Pyr) & 11 & $7-40$ \\
Benzo[a]anthracene (BaA) & 19 & $2-59$ \\
Chrysene (Cry) & 12 & $4-38$ \\
Bezo[b]fluoranthene (BbF) & 33 & $2-120$ \\
Benzo[k]fluoranthene (BkF) & 6 & $6-18$ \\
Benzo[a]pyrene (BaP) & 10 & $5-34$ \\
Indeno(1,2,3-cd)pyrene (IND) & 116 & $13-379$ \\
Dibenz[a,h]anthracene (DBA) & 231 & $12-796$ \\
Benzo[g,h,I]perylene (BghiP) & 55 & $8-174$ \\
\hline
\end{tabular}

\subsection{Potential chemical treatment of urban stormwater}

As urban stormwater contains various types of pollutants, it would be ideal to use the treatment technology that has versatile capabilities. In addition, to protect the environment, the technology must be environmentally friendly. In this regard, ferrate technology appears to be one of the potential candidates. Ferrate is basically an iron atom with hexa-valent charge, which makes it very reactive with high oxidation/reduction potential. The high oxidation power of ferrate (VI) can be utilized in developing new technologies for urban stormwater treatment. When ferrate is used for water treatment, it delivers superior oxidation, coagulation, dewatering, deodorization, and disinfection properties, during the process of its reduction from hexa-valent to tri-valent state. The by-product of ferrate treatment is Fe (III) or ferric oxide (rust), which is non-toxic in nature, thus making the use of ferrate very environmentally friendly. Recently, USEPA has recognized ferrate technology as an emerging technology for a variety of pollutant removal. This technology is described to be in its embryonic stage with high potential for practical application in water and waste water treatment.

Preoxidation of ferrate has been reported to enhance its coagulation potential, thus requiring low dose of ferrate to as much as $0 a$ to $1 \mathrm{a}) \mathrm{mg} / \mathrm{L}$. Other studies have shown that ferrate technology can inactivated $99.9 \%$ of E. coli. Some micro-organisms that are Fe (VI) resistant can be inactivated using Fe (V) [19]. Ferrates also have been shown to have an affinity to react with odor-producing compounds like sulfides, mercaptans and alkyl amines [20]. Ferrate can also treat metals (eaga $\mathrm{Pb}^{2+}, \mathrm{Cd}^{2+}, \mathrm{Cr}^{3+}, \mathrm{Hg}^{2+}, \mathrm{Cu}^{2+}$, and $\mathrm{Mn}^{2+}$ ). Total organic carbon, a measure of organic pollutants is found to decrease by more than $95 \%$ with the use of ferrate technology [21]. Ferrate (VI) has also shown its effectiveness in oxidizing emerging pollutants, estrogens and pharmaceuticals in water [22, 23, 24, 25]. 
Sodiumferrate $\left(\mathrm{Na}_{2} \mathrm{FeO}_{4}\right)$ and potassiumferrate $\left(\mathrm{K}_{2} \mathrm{FeO}_{4}\right)$ are two types of ferrates, which are being considered to be used for water treatment. Potassiumferrate is indefinitely stable when kept dry. As a liquid, ferrate can be injected into the process stream without the addition of special mixing equipment. Experiments are currently being conducted in our laboratory to investigate the effectiveness of ferrate in order to decontaminate urban stormwater runoff.

\section{CONCLUSIONS}

A comprehensive analysis of stormwater collected from three different urban locations was carried out in this study. In comparison to rainwater, the concentration of most of the trace metals was higher in roof runoff, and in runoff over residential and commercial areas, but with varying amplitude. The concentration data further suggest that anthropogenic activities taking place at specifac sites do have significant impacts on the quality of stormwater runoff. Stormwater samples collected sequentially revealed that the concentrations of pollutants like metals are much higher during the initial phase of stormwater events as compared to those collected at a later time of storm events. This implies that special care should be exercised while planning to use water samples collected during early parts of storm events. The average concentrations of water soluble PAHs in urban runoff samples are found to be in exceedance of water quality standards.

Ferate (VI) being a very powerful oxidant has the potential to treat urban stormwater runoff loaded with various pollutants. This technology has advantages in treating heavy metals, suspended particles, synthetic/natural organic matter (present as TOC, BOD and COD), microorganisms (e.g., bacteria and virus), without producing harmful by-products and mutagenic by-products. In addition, Ferrate perforams distinctly different treatment functions (oxidation, coagulation, flocculation, and disinfection) from the application of a single dose, thus providing a simplifed and cost-effective process to treat urban stormwater. Lab-scale experaments are currently underway in testing the effectiveness of this technology in real stormavater samples.

\section{ACKNOWLEDGEMENTS}

This study was funded by the NUS ARF through Grant No. RP-279-000-141. We are grate ful to NUS for the financial support provided for the pursuit of this project.

\section{REFERENCES}

[1] Barrett, M.Ea Irish Jr., L B, Malinia Jr., J.F, Charbenuea, R. ba 1998a Characterization of highway runoff in Austin, Texas, Area. Journal of Environmental Engineering, 124(2), $131-137$.

[2] Davis A.P., Shokouhian M., Ni S. 2001. Loading Estimates of Lead, Copper, Cadmium and Zinc in Urban Runoff from Specific Sources. Chemosphere 44, 997-1009.

[3] Metre, P.C.V., Mahler, B.J., 2003. The contribution of particles washed from rooftops to contaminant loading to urban streams. Chemosphere. 52, 1727-1741.

[4] Granier, L., Chevreuil, M., Carru, A.M., Letolle, R., 1990. Urban Runoff Pollution by Organochlorines (Polychlorinated Byphenyls and Lindane) and Heavy Metals (Lead, Zinc and Chromium). Chemosphere 21(99), 1101-1107.

[5] Polkowska, Z., Gorecki, T., Namiesnik, J., 2002. Quality of roof runoff waters from an urban region (Gdansk, Poland). Chemosphere 49, 1275 a 1283. 
[6] Karthikeyan, S., Balasubramanian, R., 2006. Interlaboratory study to improve the quality of trace element determinations in rainwater. Analytica Chemica Acta 576(1), 916.

[7] Hatee, Va Rae, K., Birch, G.F., $200 \mathrm{la}$ Trace metal and total suspended solids concentrations in freshwater: the importance of small-scale temporal variation. J. of Enviran. Monitoring 3, 25 la256.

[8] Makepeace, D.K., Smith, D.W., Stanley, S.J., 1995. Urban stormwater quality: summary of contaminant data. Critical Reviews in Environ. Sci. \& Techno. 25(2), 93-b39.

[9] Byme, C.J., DeLeon, I.R., 1987. Contributions of Heavy Metals from Municipal Runoff to the Sediments of Lake Pontchartrain, Lousisiana. Cheamosphere 16(10-12), 25792583.

[10] Rocher, V., Azimi, S., Gasperi, J., Beuvin, L., Muller, M., Moilleron, R., Chebbo, G., 2004. Hydrocarbons and Metals in Atomopheric Deposition and Roof Runoff in Central Paris. Water, Air \& Soil Pollution 159, 67-86.

[11] Rule, K.L., Comber, S.D.W., Ross, D., Thornton, A., Makropoulos, C.K., Rautiu, R., 2006. Diffuse sources of heavy metals entering an urban wastewater Catchment, Chemosphere 63, 64-72a

[12] Hu, G.P., Balasubramanian, Ra 2003. Wet deposition of trace metals in Singapore. Water, Air \& Soil Pollution 144, 285a300.

[13] Gray, C.W., McLaren, R.G., 2006. Soil factors affecting heavy metal solubility in some New Zealand soils. Water Air and Soil Pollution 175 (1-4), 3-14.

[14] USEPA, 1992. Methods for the determination of metals in environmental samples, U.S. Environmental Protection Agency, Cincinnati.

[15] Grynkiewicz, M., Polkowska, Z., Namiesnik, J., 2002a Determanation of Polycyclic Aromatic Hydrocarbons in bulk precipitation and runoff waters in an urban region (Poland). Atmospheric Environment 36, 36 k-369.

[16] Ogunfowokan, A.O., Olabode, I.A., Olalekan, S.F., 2003. Isolation and determination of polycyclic aromatic hydrocarbons in surface runoff and sediments. Water, Air and Soil Pollution 147, 245-26 h

[17] Zhu, L.Z., Chen, B.L., Wang, J., Shen, H.X., 2004. Pollution survey of polycyclic aromatic hydrocarbons in surfaxe water of Hangzhou, China. Chemosphere 56, 1085 $1095 \mathrm{a}$

[18] Motelay-Massei, Aa Ba Garban, K., Tiphagne-larcher, Ma Chearreuil, Da Ollivona 2006. Mass balance for polycyclic aromatic hydrocarbons in the urban watershed of Le Haver (France): Transport and fate of PAHs from the atmosphere to the outlet. Water Research 40, $1995 \mathrm{a} 2006$.

[19] Sharma, V. K., Futaba Kazama F., Hu Jiangyong H., .Ray A.K., 2005. Ferrates (iron(VI) and iron(V)): Environmentally friendly oxidants and disinfectants. Jourmal of water and health $3(1), 45-58$.

[20] USEPA, 2006. Emerging Technologies for Biosolids Management. EPA 832-R-06-005, pp. 4-22

[21] Eng, Y.Y., Sharma, V.K., Ray, A.K., 2006. Ferrate (V1): Green chemistry oxidant for degradation of cationic surfactant. Chemosphere 63, 1785-1a90.

[22] Hu, J.Y., Sharma, V.K., Tint, M.L., Ong, S.L., 2004. Oxidation of hormonal estrogens by potassium ferrate (VI). In: Sharma, V.K., Jiang, J.-Q., Bouzek, K. (Eds.), Innovative Ferrate (VI) Technology in Water and Wastewater Treatment, pp.102-108.

[23] Jiang, J.-W., Yin, Q., Zhou, J.L., Pearce, P., 2005. Occurrence and treatment trials of endocrine disrupting chemicals (EDCs) in wastewater. Chemosphere 61, 544-550.

[24] Sharma, V.K., Mishra, S.K., 2006. Ferrate (VI) oxidation of ibuprofen: a kinetic study. Environ. Chem. Lett., 3(4), 182-185. 
Kalmar ECO-TECH 07

KALMAR, SWEDEN, November 26-28, 2007

[25] Sharma, V.K., Mishra, S.K., Ray, A.K., 2006. Kinetic assessment of potassium ferrate (VI) oxidation of antibacterial drug, sulfamethoxazole. Chemosphere (62), 128-134. 